\begin{tabular}{|c|c|c|}
\hline $\begin{array}{l}\text { PKS } \\
\text { PUBLIC } \\
\text { KNOWLEDGE } \\
\text { PROJECT }\end{array}$ & $\begin{array}{c}\text { REVISTA DE GEOGRAFIA } \\
\text { (RECIFE) } \\
\text { http://ww.revista.ufpe.br/revistageografia }\end{array}$ & $\begin{array}{l}\text { OJS } \\
\frac{\text { OPEN }}{\text { OPENAL }} \\
\text { SYSTEMS }\end{array}$ \\
\hline
\end{tabular}

\title{
ESPACIALIDADE DOS RITUAIS EM CERIMÔNIAS DE CASAMENTOS CATÓLICOS: UMA ABORDAGEM COMPARATIVA ENTRE BRASIL E FRANÇA
}

\author{
Raquel Lage Tuma ${ }^{1}$, Carlos Eduardo Santos Maia ${ }^{2}$
}

${ }^{1}$ Professora Substituta no Curso de Turismo do Instituto Federal de Goiás. Email: tuma.raquel@gmail.com

${ }^{2}$ Doutor em Geografia pela Universidade Federal do Rio de Janeiro. Email: carlmaia@uol.com.br

Artigo recebido em 03/06/2017 e aceito em 29/10/2017

\begin{abstract}
RESUMO
O casamento como um rito de passagem numa perspectiva geográfica é apresentado no texto, enfatizando-se a relação espaço-tempo e cenário com objetivo de analisar as espacialidades nas cerimônias católicas. Demonstrase e analisa-se o posicionamento das personagens nos rituais mediante uma abordagem comparativa entre Brasil e França. Como procedimentos metodológicos utilizam-se a pesquisa bibliográfica no tratamento conceitual baseado em livros e artigos científicos. Os casos foram estudados nos dois países mencionados, notando-se a ocorrência dos rituais e suas relações espaciais nas sociedades. Observações, registros e entrevistas em campo foram igualmente utilizados nesta pesquisa compreensivo-explicativa na qual se identificam certos fatores e razões que contribuem para as especificidades das cerimônias nestes países.
\end{abstract}

Palavras-chave: Matrimônio, Sacramento, rito de passagem.

\section{SPACIALITY OF RITUALS IN CATHOLIC WEDDING CEREMONIES: A COMPARATIVE APPROACH BETWEEN BRAZIL AND FRANCE}

\begin{abstract}
In the present text, the wedding ceremony, as a rite of passage, is presented under a geographical perspective emphasizing the relation space-time and scenery with the objective of examining the spatiality in the Catholic ceremonies. A comparative approach between Brazil and France considers the positioning of the participants in the rite. The methodological procedures include books and scientific articles related to the matter. In both countries the rites and their spatial relationships in society were examined. In this comprehensive analysis, due observations, notes and field interviews were carried out including some factors and reasons that contribute to the specificities of the ceremonies in these countries.
\end{abstract}

Key-words: Marriage, Sacrament, Rite of Passage. 


\section{INTRODUÇÃO}

O casamento foi instituído na Igreja Católica como um sacramento que estabelece a união indissolúvel entre o homem e a mulher para constituir família, estando implicadas neste sacramento, paralelamente, as ideias de fidelidade e procriação. Embora esta concepção esteja em desacordo com os anseios das sociedades contemporâneas mais avançadas em termos de liberdades individuais que reconhecem a união entre pessoas do mesmo sexo ("casamento gay"); no catolicismo, tal ideário, gestado na cristianização das cerimônias de casamento entre os séculos X e XI (THOMSON, 1993), permanece inatacável mesmo entre tendências progressistas. Prova disto é que o atual pontífice afirmou na exortação apostólica Amoris laetitia (Alegria do amor) que "não existe fundamento algum para assimilar ou estabelecer analogias, nem sequer remotas, entre as uniões homossexuais e o desígnio de Deus sobre o matrimónio e a família"; apesar de advertir, neste mesmo documento, que "cada pessoa, independentemente da própria orientação sexual, deve ser respeitada na sua dignidade e acolhida com respeito, procurando evitar «qualquer sinal de discriminação injusta» e particularmente toda a forma de agressão e violência." (FRANCISCO, 2016).

Neste artigo, não se investigam os valores ou cânones religiosos, mas sim a espacialidade dos rituais das cerimônias de casamento no Brasil e na França, destacando-se as transformações no cenário para a realização do matrimônio, bem como as práticas ritualísticas que definem os direcionamentos e posicionamentos espaciais dos participantes nestes dois países. Os procedimentos metodológicos utilizados na produção do texto são análise bibliográfica e observações sistemáticas de cerimônias realizadas no Brasil e na França. Notese ainda que uma das autoras trabalhou durante oito anos como organizadora de cerimônias de casamento no Brasil, o que lhe confere certa experiência prática para falar do assunto. Além disso, durante o doutoramento, foram pesquisados especificamente oito casamentos de casais brasileiros. Na França, a pesquisa ocorreu entre os meses de outubro de 2014 e agosto de 2015 quando uma das pesquisadoras encontrava-se realizando doutorado sanduíche no ENEC/Sorbonne/Paris IV e o outro desenvolvia pesquisa de estágio sênior (pós-doutoral) neste mesmo laboratório. Ambos os autores fizeram pesquisa de campo inicial nas proximidades do $18^{\circ}$ arrondissement ${ }^{1}$ de Paris onde há várias lojas voltadas às cerimônias de casamento. As observações dos rituais na França foram feitas em oito cerimônias, nas seguintes igrejas: Val-de-Grâce, $5^{\circ}$ arrondissement, e Saint-Séverin, $6^{\circ}$ arrondissement, sendo ainda pesquisados quatro casais residentes em Paris. Durante as observações, foram tiradas

\footnotetext{
${ }^{1}$ Nome dado às divisões administrativas em Paris.
} 
fotografias, anotadas em cadernetas de campo as espacialidades assumidas desde a chegada até a saída dos noivos da igreja e principais formas de interações, as operações ritualísticas desenvolvidas pelos celebrante e nubentes, etc.

\section{O CASAMENTO COMO RITO DE PASSAGEM: ESPAÇO-TEMPO E CENÁRIO}

O antropólogo francês Gennep (2011, p. 29) definiu ritos de passagem como sendo "todas as sequências cerimoniais que acompanham a passagem de uma situação a outra, e de um mundo (cósmico ou social) a outro". Entre esses ritos, Gennep (2011, p. 108) inclui “os ritos de casamento, que compreendem, sobretudo, ritos de agregação definitiva ao novo meio", demarcando a vida adulta. Peirano (2003), sem se importar especificamente com os “denominados ritos de passagem", inspirada em Tambiah, traz um ponto crucial para interpretar a espacialidade das cerimônias de casamento: o ritual é uma comunicação simbólica performativa - sendo esta comunicação simbólica performativa que se toma aqui como base comparativa entre Brasil e França.

A igreja, na qualidade de espaço sacralizado, imprime à cerimônia de casamento determinadas especificidades, pois nos espaços sacralizados "há uma diferenciação de conteúdos, graus e referenciais sagrados [...] Essas considerações permitem-nos reconhecer o espaço não apenas como indispensável ao rito, mas também como definidor de intencionalidades, qualidades, prescrições, interditos, papéis e funções a ele associados" (VILHENA, 2005, p. 79).

No catolicismo romano, a igreja é o lugar sagrado próprio para a realização do ritual do casamento, onde se consuma a passagem e se realizam diversas comunicações simbólicas performativas. A primeira destas comunicações é o interdito relacionado ao casamento fora da igreja, pois os padres não estão autorizados pelo Papa a oficializar um casamento religioso fora deste local. Caso o casal tenha interesse em realizar o ritual noutro lugar com a benção do padre é preciso que se obtenha uma autorização, o que requer certo tempo de espera entre a tramitação do pedido e o consentimento, sendo necessária uma justificativa relevante.

Todavia, mesmo quando realizado dentro da igreja, o processo ritual demanda espera, algumas vezes longa, como é o caso, no Brasil, da Igreja Nossa Senhora do Brasil, na Cidade de São Paulo, que possui agenda bem cheia em alguns meses (principalmente maio, setembro e outubro) e pode acarretar demora de até cinco anos. Outros meses, entretanto, não requerem tanta espera, como é o caso de janeiro - menos procurado por coincidir com período de férias. Na quaresma, entre os meses de fevereiro e março, geralmente não são 
realizados casamentos. Destarte, a escolha da data do casamento já comunica relações simbólicas estabelecidas com os espaços-tempos privilegiados para este rito de passagem em cada cultura, indicando preferências socialmente produzidas (mês de maio-mês das noivas x quaresma, igrejas de maior status), bem como a importância que o ritual pode assumir.

$\mathrm{Na}$ França é muito mais fácil encontrar datas disponíveis nas igrejas em curto prazo para a realização deste rito de passagem. Em Paris, os meses mais procurados pelos casais são setembro e outubro, pois são meses ainda "quentes". Nos meses de julho e agosto quase não se tem casamentos nas igrejas, por serem férias. Nestes meses é mais comum os casamentos acontecerem no interior ou litoral, pois além de serem meses de verão, as famílias podem participar e viajar com mais tranquilidade para os casamentos. No mês de maio se tem alguns casamentos, mas lá é mais frequente a realização de batismos neste período.

A escolha de uma data faz-se acompanhar também da seleção do local que assume determinada "lugaridade" no ritual, no caso uma igreja onde será oficializado o rito de passagem simbolizado materialmente na soleira. "Assim, 'atravessar a soleira' significa ingressar em um mundo novo. Tal é o motivo que confere esse ato grande importância nas cerimônias de casamento..." (GENNEP, 2011, p. 37). Na qualidade de lugar do ritual, cuja soleira significa propriamente a passagem, é necessária uma aproximação afetiva e efetiva, utilizando-se de elementos alegóricos dispostos de maneira decorativa. A decoração, em efeito, não é apenas um elemento material, mas também imaginativo na constituição da igreja como lugar na data selecionada. De outro modo, "a decoração é um velho processo pelo qual se pode passar metaforicamente ao universo da beleza, da história e da lenda" (RHEIMS, 1999, p. 162) e, dir-se-ia, dos lugares.

Nas igrejas do Brasil são colocados arranjos de flores na nave principal ${ }^{2}$ e no altar (Figura 01 - setas vermelhas). Alguns casais ostentam e contratam fornecedores para fazer uma verdadeira transformação na igreja. Isto é planejado meses antes do casamento, escolhendo-se as flores (espécies, cores, tamanhos dos arranjos) combinações com velas, tecidos, etc. Assim, "a decoração apresenta-se como uma espécie de mosaico em que tudo está associado: quer os trabalhos do homem quer os efeitos da natureza, mais ou menos domesticados" (RHEIMS, 1999, p. 159). Desenvolve-se então uma cenografia onde se interrelacionam o cenário, os atores e o espaço (MACHADO, 2006).

${ }^{2}$ Corredor principal por onde as pessoas entram na igreja e ocorrem todos os cortejos. 
Figura 01- Igreja São João Evangelista decorada com velas e flores no casamento, em Goiânia.

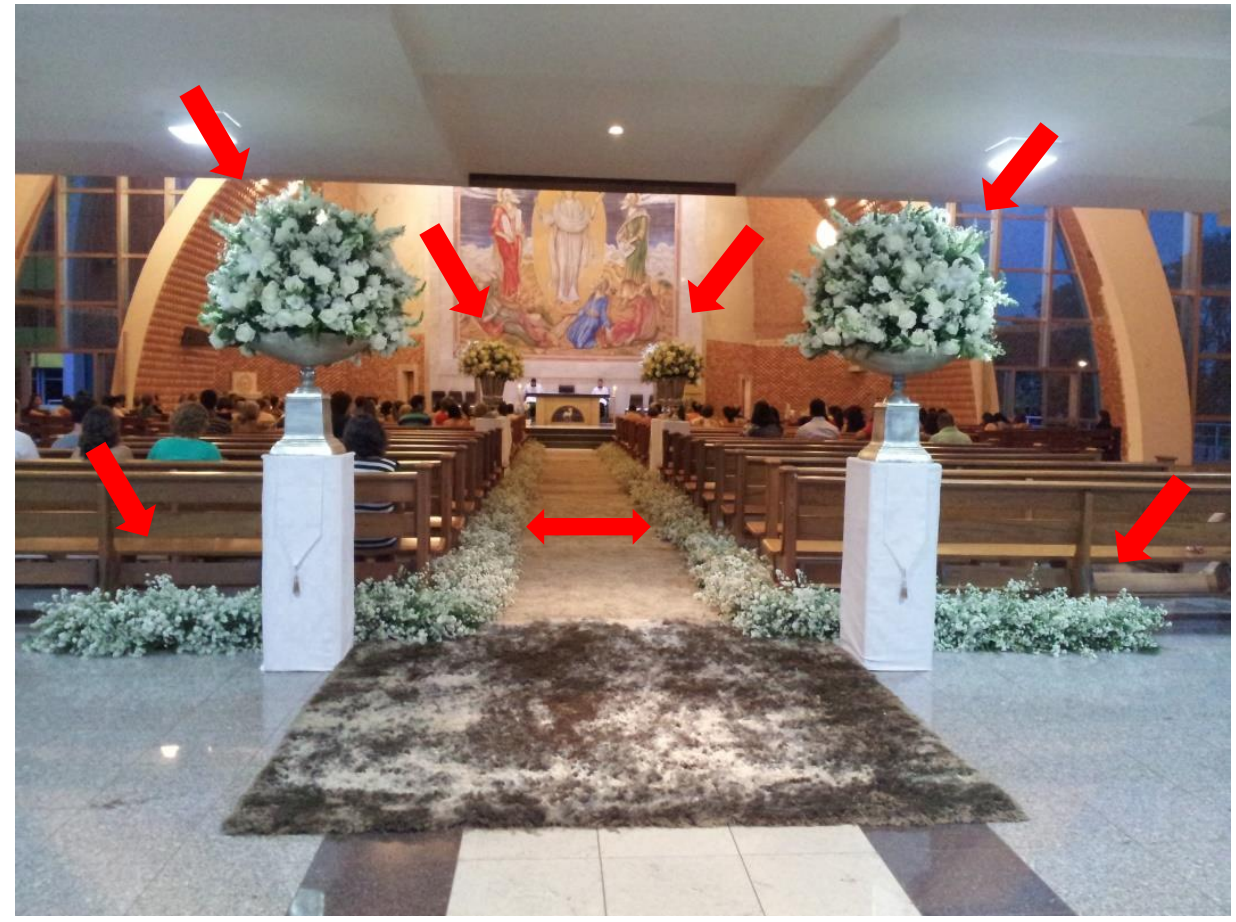

Foto: a autora (set/2013)

Fonte: Arquivo pessoal da entrevistada

O serviço de decoração é quase sempre dirigido um profissional, cuja equipe que chega pela manhã, ou por volta de três horas antes da cerimônia, dependendo da sua complexidade. Cabe ressaltar que, "para que uma decoração seja satisfatória, é desejável que existam entre ela e aquele para quem foi concebida, laços estéticos e privilegiados que, por vezes, têm raízes no seio da afectividade" (RHEIMS, 1999, p. 159), e por isso, conforme foi dito, a decoração é indispensável para a lugaridade da igreja durante o ritual. Quando é composta por arranjos de flores que podem ser facilmente carregados, os decoradores os montam em seus próprios galpões e depois os levam prontos somente para serem colocados nos locais ao longo da nave principal e no altar.

Algumas vezes o trabalho dentro da igreja precisa ser iniciado no período da manhã para que se consiga produzir a decoração no próprio ambiente. Note-se que cada igreja faz exigências ou restrições em relação ao material e à forma de colocação. Há alguns casos em que a igreja fornece uma lista de profissionais autorizados a entrarem e produzirem a decoração, proibindo-se a contratação de outros não cadastrados. Em alguns casamentos são 
colocados os genuflexórios ${ }^{3}$, que podem ser da própria igreja ou, quando esta não os possui, são colocados pelos decoradores, conforme combinado previamente com os noivos, para que no momento da benção e/ou da comunhão o casal possa se ajoelhar, embora não seja em todo ritual que se tem a comunhão, havendo somente quando os noivos a solicitam ao padre. $\mathrm{O}$ genuflexório também pode ser usado no momento da bênção, porém não se faz necessário, sendo mais comum abençoar o casal no momento em que se encontra de pé. Evidentemente que a maior ou menor ostentação varia de acordo com o poder aquisitivo dos noivos, ou com as economias que estes fizeram a fim de dispensar no matrimônio.

O cenário nas igrejas na França, mais especificamente naquelas que se pesquisou em Paris, tem perfil bem diferente e sua preparação começa cerca de uma hora antes do casamento, quando o noivo, os pais, os familiares e/ou amigos auxiliam na pouca decoração e na distribuição do livreto com o roteiro da cerimônia. A decoração é bem singela e às vezes imperceptível em uma foto (Figura 02 - setas amarelas), que pode ser uma rosa (Figura 03), ou um pequenino buquê de flores (Figura 04). Notou-se que nem sempre houve alguma decoração na igreja. Nos casamentos observados e pesquisados, os noivos não demonstraram o costume de contratar fornecedores para fazer este serviço, havendo casais que não colocaram sequer uma flor nas cadeiras, assim como não foram todos que distribuíram o livreto da cerimônia. Não foram postas também flores no altar, tapetes ou qualquer outro tipo de decoração ou adereços.

A cenografia nas igrejas em Paris se altera mais com a presença das personagens na hora do ritual (os noivos, o padre, os convidados, os pais, os familiares) do que pela decoração. Percebeu-se ainda nos casamentos observados e pesquisados que as igrejas raramente ficam com todos os assentos completos, pois em geral possuem poucos convidados. Outro detalhe é que no altar normalmente há duas cadeiras para os noivos se sentarem (tal fato não acontece no Brasil) e o genuflexório para se ajoelharem (Figura 05). Uma das explicações para haver um ritual mais pomposo no Brasil, no que se refere à decoração, relaciona-se ao fato de aqui ser possível realizar o casamento civil neste recinto, ou seja, a igreja torna-se o lócus do rito de passagem tanto religioso, quanto civil. Já isto não é possível em Paris, pois o casamento civil deve ser necessariamente celebrado na Mairie ${ }^{4}$. Os preços

\footnotetext{
${ }^{3}$ Móvel utilizado para ajoelhar-se durante os rituais na igreja para fazer a oração no momento da comunhão. No caso de casamento, são menores, para duas pessoas ou individuais.

4 A tradução para Mairie é 'prefeitura'. É um órgão municipal francês e, em Paris, é dividido por regiões (arrondissements) e cada morador deve sempre se dirigir àquela de sua residência, ou seja, se habita no $14^{\circ}$
} 
dos serviços prestados pelos decoradores na Cidade Luz também podem ser indicados como fatores da composição decorativa singela nas igrejas parisienses. Na França, uma decoração com dois grandes vasos de flores no altar, mais outros dois vasos na entrada da igreja, dois buquês de flores em cada fileira de bancos e folhagem para fazer um caminho lateral ao longo da nave da igreja custaria em torno de três a cinco mil euros, dependendo do fornecedor. Uma decoração semelhante a esta no Brasil, convertendo-se o real para euro, custaria cerca de 800 a 1400 euros.

Figura 02- Decoração da igreja em Paris com botões de Figura 03- Detalhe da decoração rosa branca e gypsophila, quase não se nota na foto.

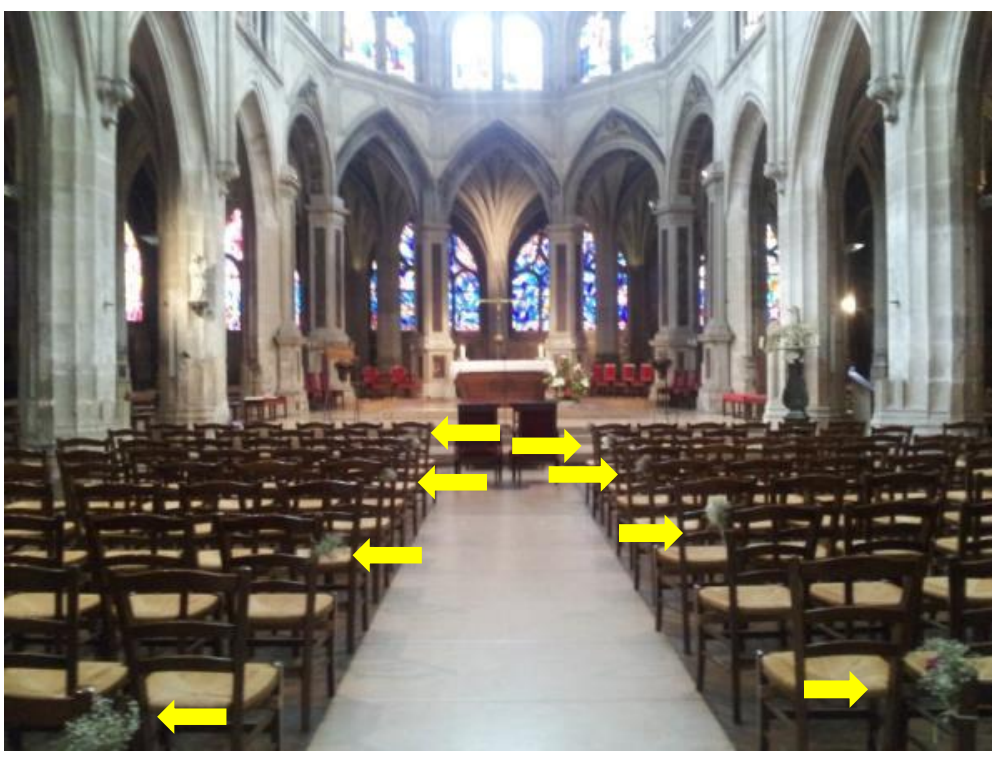
da igreja com apenas uma rosa branca e gypsophila (pequenas florezinhas

Foto: a autora (jun/ 2015)

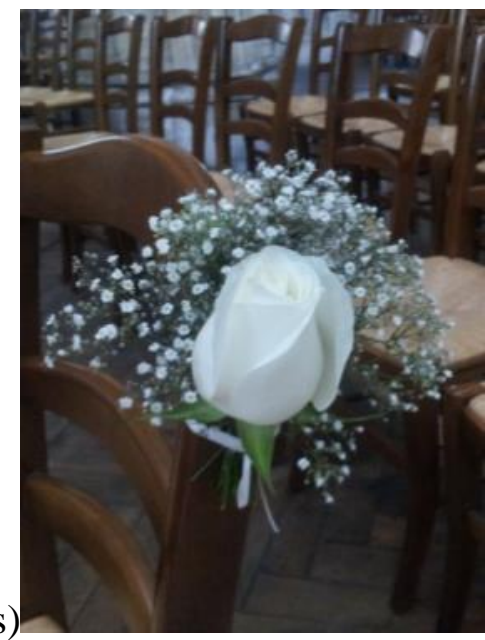

brancas)

Foto: a autora (jun/ 2015)

\section{RITUAIS DE CHEGADA E ENTRADA}

O ritual do casamento pode ter algumas variações no que tange às entradas e aos posicionamentos de cada personagem em diferentes cerimônias, mesmo que seja numa mesma cultura, seja no Brasil ou na França, ou até mesmo em uma mesma cidade. Porém, apresenta-se, nesta parte, o que é usual em cada um destes países a partir das experiências vivenciadas em cada lugar. Destacam-se as palavras de Parkin (1992, p. 12) quando diz que “ritual é considerado por privilegiar ação física; mas é uma ação que só pode ser entendida

arrondissement em Paris, o residente deve se dirigir à mairie do $14^{\circ}$ arrondissement. Possui diversas funções, dentre elas estão: criação de classes escolares, registro de alunos às escolas, atribuição de propriedades e realização de casamentos. 
como movimento no sentido corporal ou posicionamento em relação a outros movimentos corporais e posições." ". Para o autor a relevância na abordagem do ritual relaciona-se "com a direcionalidade" que é "marcada pelos participantes posicionados em relacionamentos espaciais entre si” (PARKIN, 1992, p. 16). No ritual do casamento nas igrejas nota-se isto pois há posicionamentos, direcionamentos e movimentos corporais durante toda a cerimônia, conforme será descrito. Paralelamente, por ocorrer em lugares sagrados, "o simples ato de adentrá-los já é um ritual. As portas que dão acesso a seus interiores são tidas, no âmbito da sensibilidade religiosa, como liminares, lugares de passagem, que separam, relacionam, condensam e fundem mundos" (VILHENA, 2005, p. 114-115)

Figura 04- Decoração na Igreja em Paris, com um pequeno buquê de flores e fitas amarradas

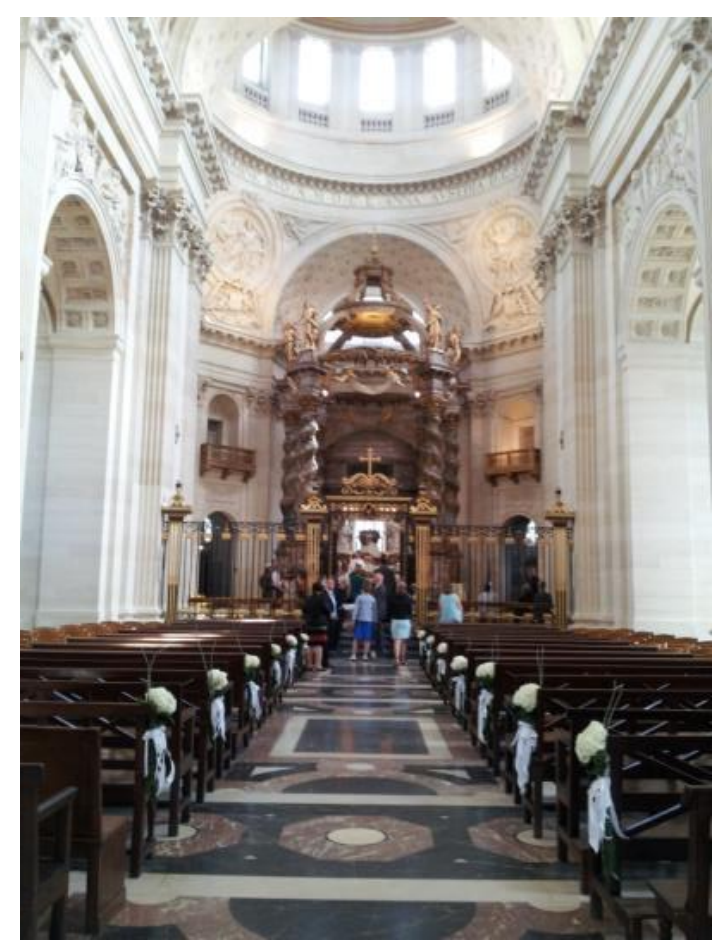

Foto: a autora (jun/ 2015)

No Brasil, o ritual inicia-se com a chegada dos convidados, que se acomodam nos bancos destinados à comunidade. Há não mais de três décadas o costume era de que os convidados da noiva deveriam ficar do lado esquerdo e os do noivo, do lado direito, porém

\footnotetext{
5 'ritual is held to privilege physical action; but it is an action that can only be understood as bodily movement towards or positioning with respect to other bodily movements and positions.' (PARKIN, 1992, p. 12). 
isso caiu em desuso. Comumente, o noivo e sua família estão na igreja recebendo os convidados, embora hoje em dia não se tenha mais a obrigatoriedade desta etiqueta. Quando é dado o horário agendado ao casamento, a noiva chega e permanecesse no carro enquanto o(a) cerimonialista organiza os pares e posiciona as personagens por ordem de entrada do lado de fora da igreja. Segue-se uma regra para todos os casais: o homem oferece o braço esquerdo para a mulher. A seguir serão apresentados os posicionamentos segundo padrões familiares convencionais (ou seja, supondo-se que ambos os noivos possuem pai e mãe. Note-se que, na ausência de um destes, outra pessoa atua representando esta personagem), lembrando-se que as coordenadas são de quem está no fundo da igreja olhando para o altar.

Figura 05- Cadeiras e genuflexórios posicionados à frente da igreja para os noivos

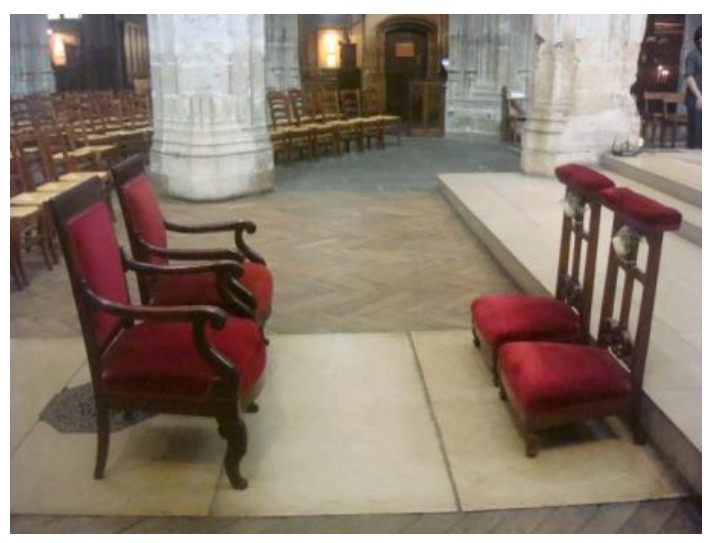

Foto: a autora (jun/ 2015, Igreja SaintSéverin, Paris)

Assim que estão todos posicionados e prontos, o(a) cerimonialista dá o comando aos músicos para tocarem a música que foi previamente escolhida pelo casal para a entrada do noivo. Neste momento, o padre está na parte central do altar e todos os convidados se levantam. O noivo adentra acompanhado geralmente de sua mãe pela porta da frente da igreja e a leva até o altar, do lado direito, e cerca de dois passos adiante, ele posiciona-se ao lado direito do altar no final da nave onde ambos aguardam em pé. Em seguida, geralmente toca-se outra música para a entrada dos pais (pai do noivo com mãe da noiva), que passam por toda a nave e o pai do noivo deixa a mãe da noiva no altar do lado esquerdo, na mesma linha onde a mãe do noivo ficou, posicionando-se ao lado desta. Também é possível que o pai do noivo fique ao lado da mãe do noivo até que o pai da noiva chegue ao altar. Simbolicamente, tem-se 
aqui representados aquilo que Gennep (2011) chama de ritos de agregação, pela união das duas famílias na cerimônia na espacialização ritualística.

Enquanto ainda os pais estão na metade do caminho da nave, dá-se a ordem para os casais de padrinhos começarem a entrar, que podem ser primeiro os casais que ficam do lado da noiva e depois do lado do noivo, ou casal a casal alternadamente. Ao chegarem à frente, os padrinhos do lado da noiva ficam do lado esquerdo e os do noivo, à direita (Figura 06). Em alguns casamentos os padrinhos ficam nas primeiras fileiras destinadas aos convidados (Figura 07), que são previamente reservadas pela equipe de cerimonial, noutros ficam atrás dos pais (com ou sem cadeiras para se sentarem), respeitando também a regra que lado esquerdo é destinado aos padrinhos da noiva e o direito, aos do noivo. Raramente há apenas um ou dois casais de padrinhos, é muito normal terem acima de quatro casais de cada lado, mas não há número definido para isto. Alguns padres restringem o número de assinaturas durante o ritual e, quando isto acontece, o cerimonialista coleta as assinaturas dos outros casais antecipadamente para que os noivos tenham este documento como recordação.

Figura 06- Posicionamento dos participantes: situação 1

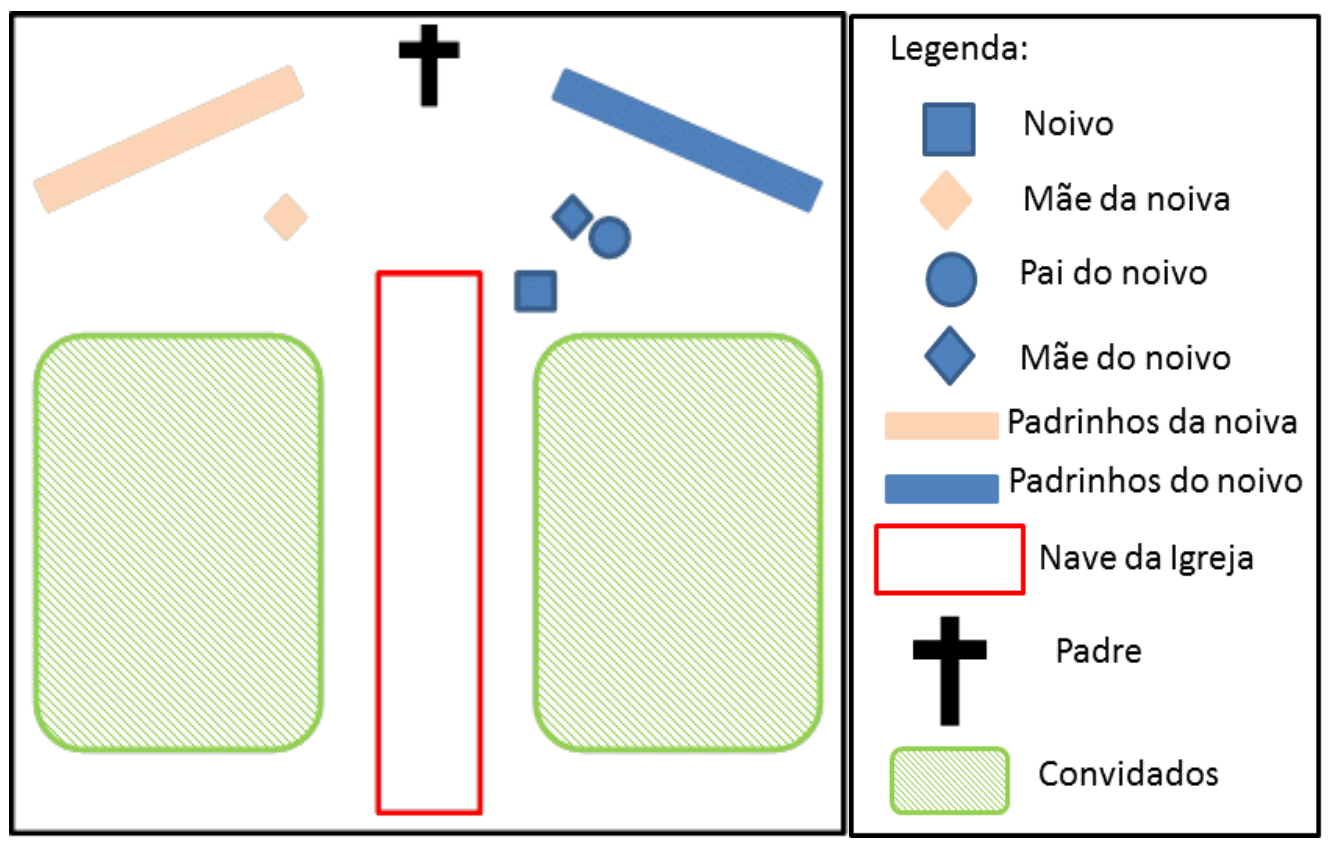

Organização e Elaboração: A autora (2016)

Uma terceira possibilidade, não tão usual, é quando os pais ficam no primeiro banco, na fileira dos convidados, próximo à nave, igualmente reservada para este fim, e a seguir, ao 
seu lado, ficam os padrinhos (Figura 08). Ressalte-se que o cortejo também pode se iniciar com os padrinhos, seguindo-se dos pais e por último o noivo e sua mãe.

Em seguida, é a vez da entrada das crianças, daminhas de honra e/ou pajens. Hoje em dia, quando há muitas crianças nas famílias dos noivos, alguns pedem para elas levarem santos, bíblia, terço, ou não portam nada, podendo, neste momento, trazer ou não as alianças. Outra possibilidade é de as alianças serem trazidas no momento da benção destas, que acontece na hora dos noivos as colocarem, por crianças, avós, ou alguém especial. Por último, vem a florista, geralmente menina, para jogar as pétalas ou folhas na entrada da noiva. Todas essas crianças ficam sentadas à frente no altar, podendo ser do lado direito ou esquerdo, ou nas laterais, ou também nos bancos dos convidados. Geralmente ficam mais próximas dos seus pais, não havendo um rigor neste posicionamento.

Figura 07- Posicionamento dos participantes: situação 2

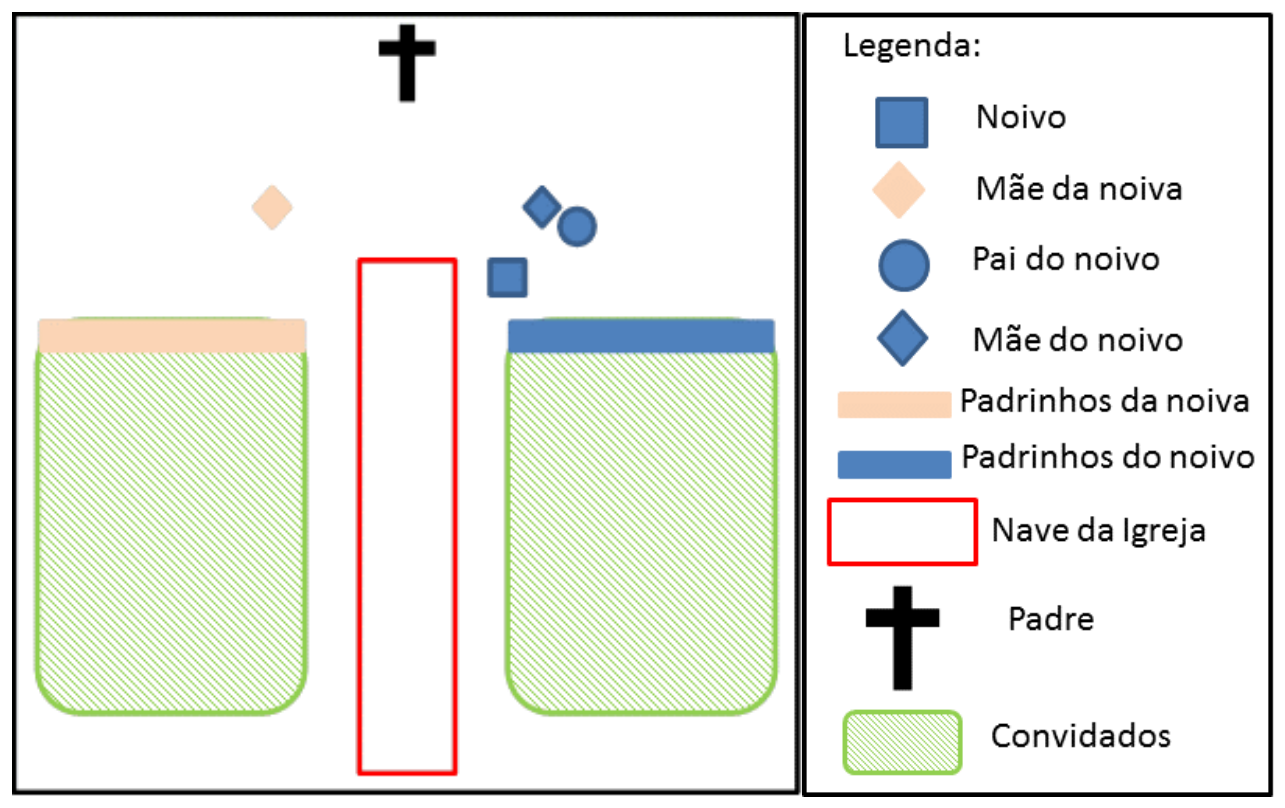

Organização e Elaboração: A autora (2016) 
Figura 08- Posicionamento dos participantes: situação 3

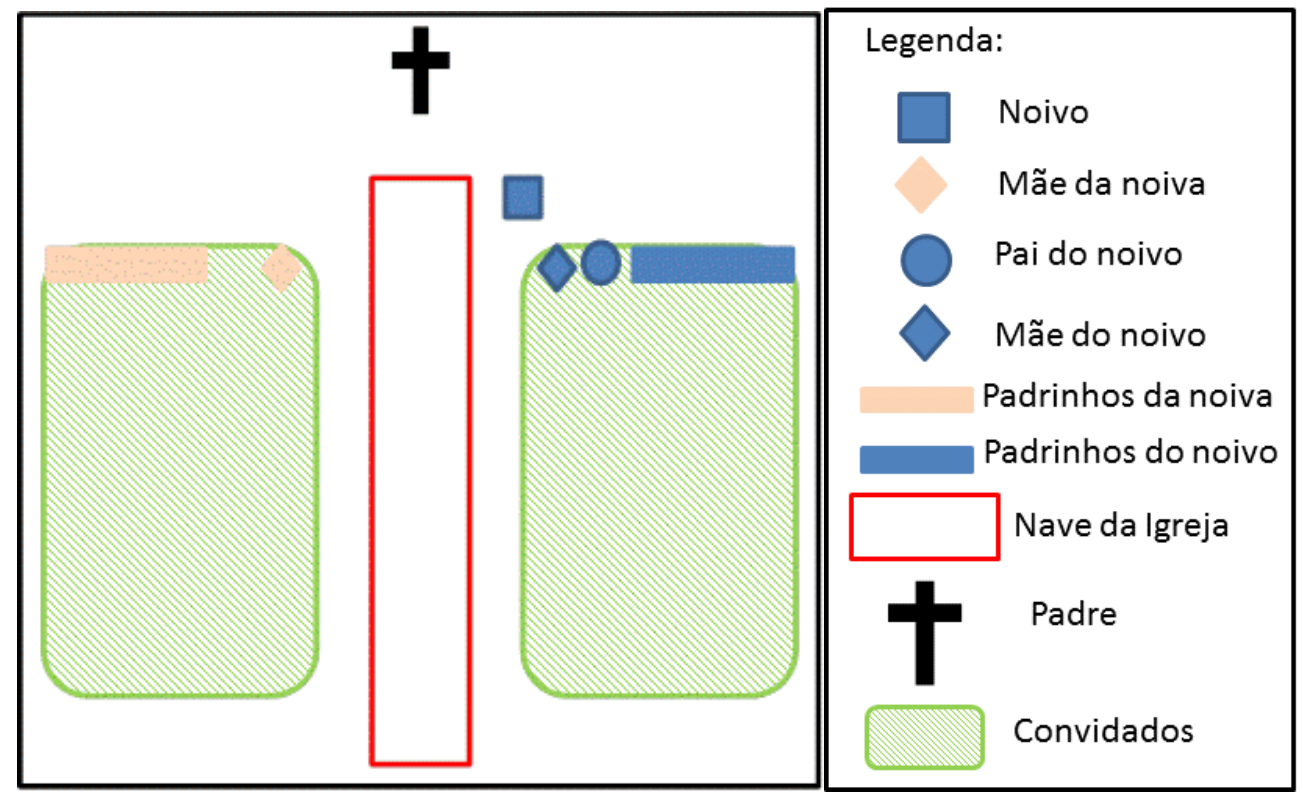

Organização e Elaboração: A autora (2016)

Após a florista, fecham-se as portas da igreja para preparar a noiva. O(A) cerimonialista ajuda a noiva a sair do carro, arruma o vestido e o véu e relembra-a como segurar o buquê, tudo isso em poucos instantes. O pai fica à esquerda da noiva, oferecendolhe o braço direito. É o único casal que entra ao inverso, ou seja, o homem do lado esquerdo e a mulher do lado direito, o que configura no ritual uma hierarquia simbólica de destaque no posicionamento à direita. Em seguida, toca-se a música de entrada da noiva e abrem-se as portas para que entrem. Durante o percurso até o altar, a noiva olha para o noivo e os convidados, sorrindo discretamente, a fim de mostrar que os viram, mas mantendo a 'etiqueta' para o momento. Ao chegar próximo do altar quem a acompanhou dá-lhe um beijo na testa ou na bochecha, havendo a troca de acompanhamento entre o pai que a levou e o noivo, os quais se cumprimentam apertando as mãos e/ou algumas vezes com um abraço. Após, o noivo cumprimenta a noiva também com um beijo no rosto e a recebe, oferecendo-lhe o braço esquerdo, permanecendo a seu lado durante o ritual. (Figura 09). Estes primeiros beijos são relativamente comedidos, avigorando a performance sagrada. Todavia

O beijo envolve o sentido do tato, do paladar, do olfato, mas também envolve sentimento e um significado, que pode ser de paixão ou de indiferença. Envolve também uma noção de direção, podendo apontar para um desfecho da relação (um beijo frio, por exemplo) ou para um aprofundamento da mesma (um beijo apaixonado). E pode, ainda, conter elementos da ordem do ideal - romântico, sagrado ou religioso - quando se realiza também na metáfora do beijar o sapo, no ato de beijar a mão dos avós, ou no ritual de beijar o santo. Esses sentidos não são 
vividos pelas pessoas de maneira isolada, mas apreendidos como um todo. (FREITAS et al., 2017, p. 152)

\section{RITUAIS DE OFICIALIZAÇÃO}

A partir do momento que a noiva chega ao altar, o padre profere as palavras de boas vindas e inicia-se a parte litúrgica, enaltecendo o valor do matrimônio. Convém observar que

...os ritos em espaços declaradamente religiosos exigem, na maioria das vezes, o concurso de especialistas do sagrado (...) Nesses espaços, portanto, são engendradas formas de poder sagrado. O que equivale dizer que, com a distribuição de funções, institui-se uma ordem hierárquica segundo a qual algumas palavras, práticas e gestos são restritos a uns e vetados a outros..." (VILHENA, 2005, p. 118-119)

Em sequência têm-se a primeira leitura, o salmo, a segunda leitura, podendo esta ser lida por padrinhos ou familiares. Continuando, o sacerdote lê o evangelho e faz a homília ${ }^{6}$. Tem-se então o rito sacramental do matrimônio, quando o padre declama:

Caros noivos, N. e N. viestes a esta Igreja, para que, na presença do sacerdote e da comunidade cristã de contrair matrimônio seja marcada por Cristo com um sinal sagrado. Cristo abençoa com generosidade o vosso amor conjugal. Já vos tendo consagrado pelo batismo, vai enriquecer e fortalecer-vos agora com o sacramento do Matrimônio, para que sejais fieis um ao outro por toda a vida e possais assumir todos os deveres do Matrimônio. (PARÓQUIA NOSSA SENHORA DO BRASIL, 2016, p. 3).

Figura 09- Posicionamento dos participantes: situação 4

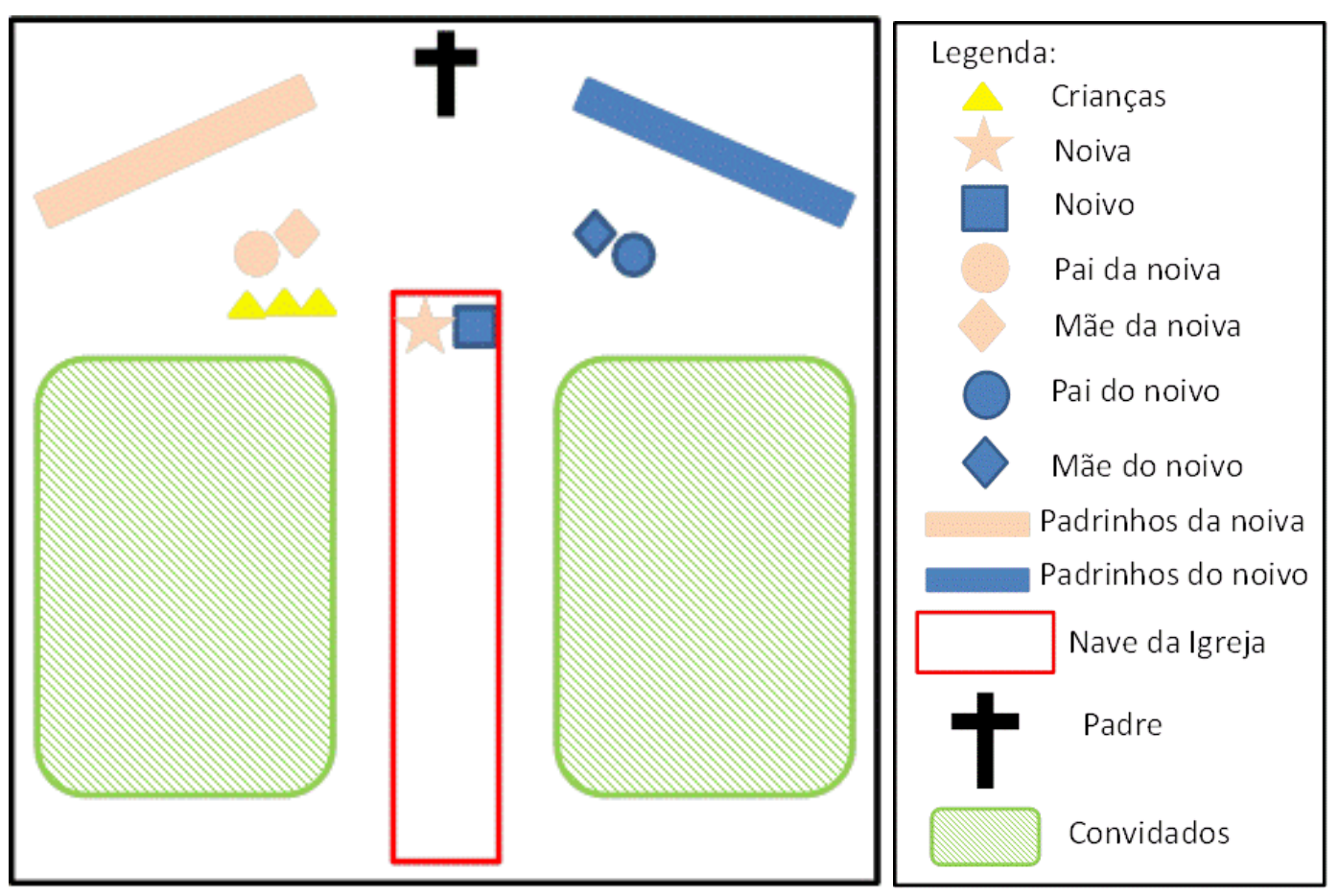

Organização e Elaboração: a autora (2016)

\footnotetext{
${ }^{6}$ Discurso que instrui os fiéis sobre a religião, considerada como uma 'conversa' para explicar os textos bíblicos, ligando-os à realidade da comunidade.
} 
Segue-se o diálogo antes do consentimento, que é conhecido por aqueles que assistem ao ritual como a 'hora do sim', quando o padre indaga aos noivos:

Sac.: N. e N. viestes aqui para unir-vos em Matrimônio. Por isso, eu vos pergunto perante a Igreja: É de livre e espontânea vontade que o fazeis?

\section{Noivos: Sim!}

Sac.: Abraçando o Matrimônio, ides prometer amor e fidelidade um ao outro. É por toda vida que prometeis?

Noivos: Sim!

Sac.: Estais dispostos a receber com amor os filhos que Deus vos confiar, educandoos na lei de Cristo e da Igreja?

Noivos: Sim! (PARÓQUIA NOSSA SENHORA DO BRASIL, 2016, p. 4).

Logo após, o sacerdote solicita que os noivos deem um ao outro a mão direita para que possam manifestar o consentimento em selar a união e pede primeiro que o noivo repita as palavras a seguir e depois a noiva: "Eu, N. te recebo, N., por minha(meu) esposa(o) e te prometo ser fiel amar-te e respeitar-te na alegria e na tristeza, na saúde e na doença, todos os dias da nossa vida.” (PARÓQUIA NOSSA SENHORA DO BRASIL, 2016, p. 4). Com esta declaração dos noivos, o padre dá a aceitação deste consentimento e, no final, diz: "Ninguém separe o que Deus uniu.” (PARÓQUIA NOSSA SENHORA DO BRASIL, 2016, p. 4). Finalizada esta parte, toca-se a música da entrada das alianças, mas se as alianças já foram trazidas pelas damas de honra ou pajem, as crianças as levam até o padre. Toca-se a música de benção das alianças e o padre solicita para que as entreguem um ao outro em sinal de amor e fidelidade, pedindo que cada um repita: "N., recebe esta aliança em sinal do meu amor e da minha fidelidade. Em nome do Pai, e do Filho e do Espírito Santo." (PARÓQUIA NOSSA SENHORA DO BRASIL, 2016, p. 5). É normal que os noivos deem um beijo na aliança após serem colocadas nas mãos. Ao final deste ato, o padre diz que os noivos podem se beijar. $\mathrm{Na}$ sequência o sacerdote faz a oração dos fieis, a liturgia eucarística e o rito da comunhão, quando há, pois nem sempre os noivos fazem a comunhão.

$\mathrm{Na}$ França, os primeiros a chegarem são os familiares e alguns amigos que auxiliam na feitura da decoração na igreja, com uma flor ou buquês de flores presas às cadeiras que estão no corredor, ou seja, mais próximas da nave onde será o cortejo. Deixam-se ainda sobre as cadeiras ou bancos os livretos que constam todo o roteiro do casamento, inclusive as canções. Estas canções geralmente são religiosas e/ou instrumentais. Por isto, tem-se somente um(a) organista e as músicas com letras religiosas são acompanhadas pelo padre e pelos presentes. Algumas vezes há um(a) musicista, ou outro profissional para tocar outro instrumento, como exemplo, o violoncelo.

O noivo chega, verifica alguns detalhes, escuta as observações finais do sacerdote e interage com familiares e amigos. Os convidados aproximam-se e ficam do lado de fora da 
igreja conversando. Comumente, a noiva chega, fala com os amigos e familiares, tira fotos e o padre passa as últimas informações (Figura 10). Aos poucos, os convidados entram e tomam os seus lugares.

Dado o horário agendado da cerimônia, começam o ritual de oficialização, que se subdivide em quatro partes. A primeira é a acolhida, quando todos os convidados levantam-se para receber os noivos, os pais e as mães, havendo um cântico religioso. Na acolhida, é usual iniciar o cortejo com o padre entrando pela nave com uma música. Em seguida, faz-se a entrada do noivo com sua mãe do lado esquerdo. Ele a deixa na primeira fileira de bancos junto com os convidados e fica em pé, do lado direito da nave da igreja. Poucas vezes os pais e padrinhos fazem o cortejo após o noivo. Geralmente eles ficam posicionados na primeira fileira do banco, ao lado dos pais. Além disso, são poucos padrinhos, cerca de quatro pessoas e não são sempre homem e mulher como um par, podem ser dois homens ou duas mulheres também. As damas de honra e os pajens entram em seguida, ficando também na primeira fileira, ou nos bancos da frente nas laterais da igreja. Vê-se também daminhas e pajens entrando logo após a noiva, porém o mais praticado é que entrem todas as crianças à frente da noiva e de seu pai. Quando acontece dos padrinhos e pais participarem do cortejo, quem faz o serviço do cerimonialista para colocar cada um na ordem de entrada são as mães (da noiva ou do noivo) ou amigas, ou familiares. 
Figura 10 - Noiva conversando com o padre para verificar os últimos detalhes

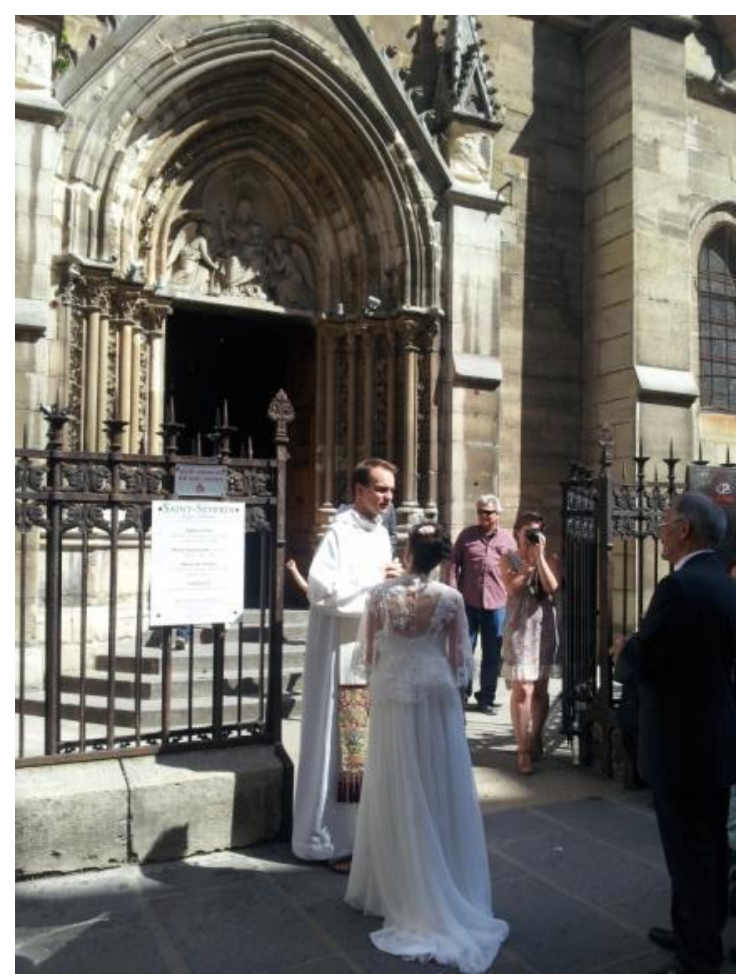

Foto: a autora (jun/ 2015, Igreja SaintSéverin, Paris)

Após as crianças, entram a noiva com o seu pai. Não há um rigor, algumas vezes a noiva fica à direita e outras à esquerda de seu pai. Como não há um cerimonialista organizando todo o ritual e não fazem ensaios antes do casamento, a troca entre o pai da noiva e o noivo (assim como a posição de entrada) também não segue uma regra, às vezes se cumprimentam, às vezes não. Porém, a posição que o noivo assume ao lado direito da noiva, esta sim é respeitada. Entretanto, o casal é instruído pelo próprio padre anteriormente e, se necessário, até na hora da troca. Quando a noiva fica ao lado do noivo, por causa da cadeira, o vestido e o véu embolaram-se, então, as mães (da noiva e/ou do noivo) e/ou madrinhas acabam arrumando o vestido e o véu, pois não há um(a) cerimonialista para fazer isto. Na figura 11 demonstra-se o posicionamento fixo dos personagens até este instante. 
Figura 11- Posicionamento dos participantes: situação 5

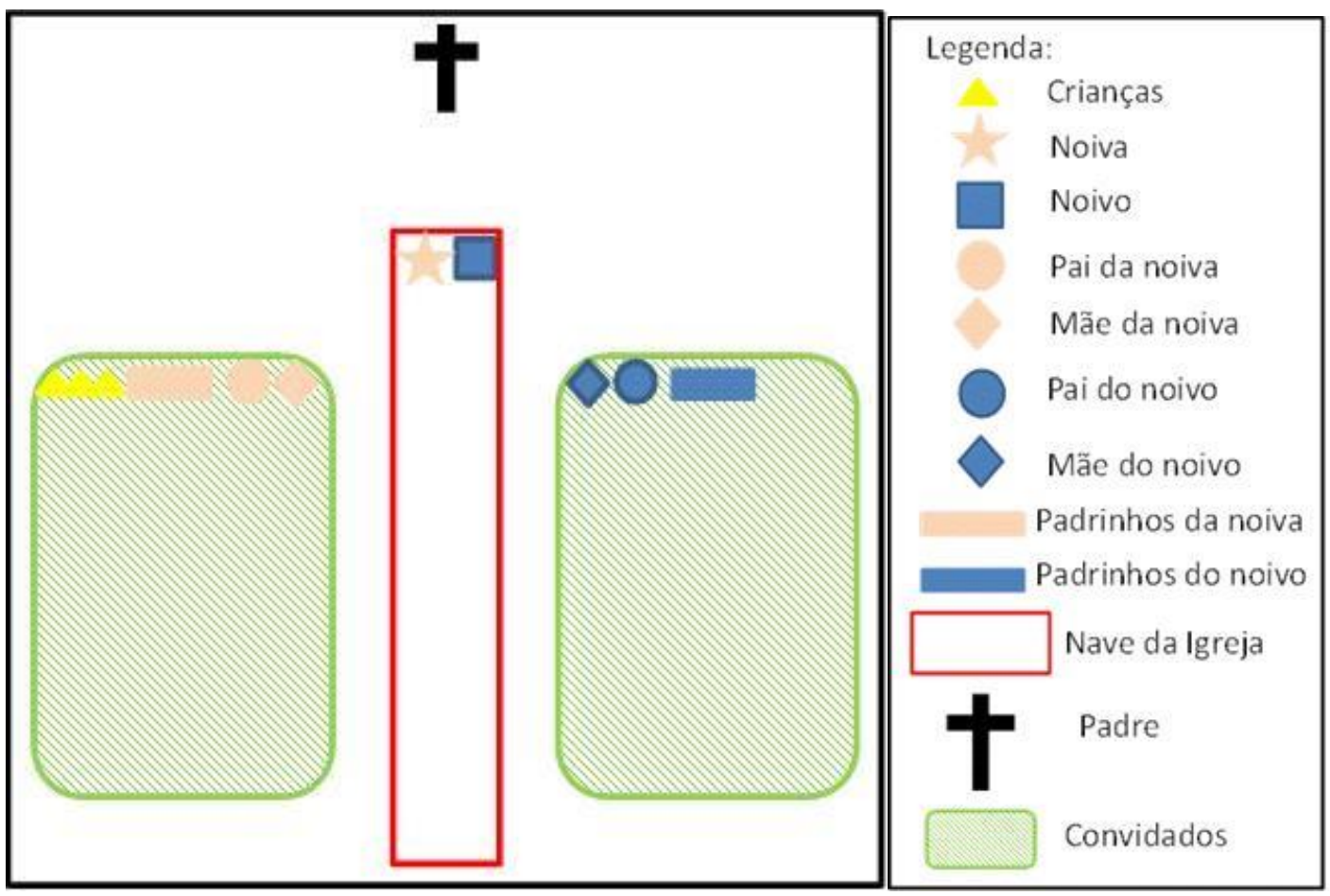

Organização e Elaboração: A autora (2016)

$\mathrm{Na}$ França, o padre continua o ritual religioso, com a segunda parte, que é a liturgia da palavra. Os noivos podem escolher juntamente com o padre os textos marcantes durante a preparação do casamento, fazendo parte desta etapa: a primeira leitura, o salmo, a aleluia (cantada), o evangelho e a homília. "O rito expresso em orações, leituras, cânticos, silêncios, pregações, gestos, danças, prostrações, posturas corporais, procissões internas, elevações é a vida que anima o espaço sagrado" (VILHENA, 2005, p. 114-115). É nesta segunda parte que os noivos proferem os votos preparados previamente um ao outro.

A terceira parte é o sacramento do matrimônio. Neste momento, o padre convida os noivos e os padrinhos para ficarem em pé. Estes ficam ao lado de seus respectivos afilhados, um passo atrás. Em seguida, o padre inicia o diálogo inicial, quando ele pergunta aos noivos: "N. e N. Vocês escutaram a palavra de Deus que revela a grandeza do amor humano e do casamento. Vocês irão se comprometer um ao outro pelo casamento. É livremente e sem coerção?"7. Os noivos respondem separadamente: Sim. O padre indaga novamente: "Ao

\footnotetext{
7 “N. e N. vous avez écouté la parole de Dieu qui révèle la grandeur de l'amour humain et du mariage. Vous allez vous engager l'un envers l'autre dans le mariage. Est-ce librement et sans contrainte ?"
} 
envolver-se na via do casamento, vocês prometem amor mútuo e respeito?"8. Os futuros esposos dizem: Sim. O padre faz a última questão: "Vocês estão prontos a acolher os filhos que Deus lhes dar e a educa-los segundo o Evangelho do Cristo e na Igreja?"9 Mais uma vez o casal afirma: Sim.

Segue-se a troca do consentimento quando o padre pede para que manifestem a anuência e digam: "Eu, N., te recebo N. como minha (meu) esposa(o) e te prometo ser fiel, na felicidade e nas provações, na saúde e na doença, por amar-te todos os dias da minha vida." 10 Feito isso, o padre dá a bênção ao consentimento e, após, ocorre a bênção e a troca das alianças, quando os noivos repetem: "N., recebe esta aliança em sinal de meu amor e de minha fidelidade (em nome do Pai, do Filho, do Espírito Santo)". Por fim, o sacerdote faz a bênção nupcial. Estes dois momentos são o ápice da emoção no ritual, sendo unânime segundo as entrevistadas. Maia (2010, p. 98) aponta que "os rituais têm um conteúdo emocional e produzem interações espaciais." Neste sentido, a emoção e o movimento espacial são fatores essenciais para a existência do ritual.

A quarta parte refere-se à oração da igreja composta pela oração dos esposos, que os recém-casados juntos oferecem a Deus. Compõe-se da primeira oração, que é preparada antecipadamente por eles; da oração universal, quando podem rezar pela família, pelas pessoas que sofrem; e finaliza-se com o Pai Nosso. Além disso, ainda se tem a liturgia da eucaristia, quando os noivos e aqueles que desejarem podem fazer a comunhão.

\section{RITUAIS DE SAÍDA}

No Brasil, após a comunhão, têm-se os ritos finais. No encerramento, toca-se uma seleção de músicas para as assinaturas dos noivos e das testemunhas. Reforça-se que não é qualquer padre que admite que todos os casais de padrinhos assinem, sendo dado este direito somente àqueles que constam na certidão, conforme foram entregues os documentos previamente. Porém há alguns padres que consentem que façam as assinaturas em uma folha separada ou no próprio documento, no espaço em branco abaixo. Esta parte é importante pois “o ritual de casamento religioso inclui a participação e a assinatura de inúmeras testemunhas

\footnotetext{
8 "En vous engageant dans la voie du mariage, vous vous promettez amour mutuel et respect. Est-ce pour toute votre vie?"

9 “Etes-vous prêts à accueillir les enfants que Dieu vous donne et à les éduquer selon l’Évangile du Christ et dans foi de l'Église ?"

10 “Moi, N. je te reçois N. comme épouse (époux) et je te promets de te rester fidèle, dans le bonheur et dans les épreuves, dans la santé et dans la maladie, pour t'aimer tous les jours de ma vie."
} 
que vinculam os nubentes e fazem-se co-responsáveis pelo cumprimento das finalidades do casamento consideradas em cada religião" (LOPES et al., 2006, p. 60).

Conforme os padrinhos vão assinando o documento, já saem e ficam perfilados fora da igreja, a partir da porta principal. Outra variação é o casal assinar o documento e voltar para os seus lugares e depois tocar uma música para a sua saída. É comum fazer fotos com família, padrinhos, damas e pajens à medida que cada personagem levanta-se para sair da igreja. Esta é uma recordação que estará nos álbuns.

Quando os padrinhos chegam à porta de saída, formam um corredor e recebem um pouco do tradicional arroz para jogarem nos noivos no momento que eles saírem. Isto tem o significado de fertilidade e sorte no casamento. Algumas igrejas proíbem o arroz, pela sujeira que é feita, pois o grão é muito pequeno e penetra em pequenos vãos do piso, dificultando a limpeza. Então, surgiram outras opções, podendo ser papel picado, pétalas de rosas ou bolinhas de sabão.

Outra possibilidade no ritual de saída é os padrinhos saírem depois dos pais e crianças, entretanto, o que tem sido mais usual é a primeira forma, ou seja, os padrinhos saírem após as assinaturas. Sendo assim, depois dos padrinhos, saem as crianças, os pais do noivo, os pais da noiva, ainda em continuação com as músicas escolhidas para as assinaturas da certidão. Mais uma alternativa de saída, porém menos comum, é quando os noivos saem primeiro, seguidos das crianças, dos pais da noiva, pais do noivo e padrinhos. Para a saída dos noivos, toca-se outra música, geralmente mais alegre. Este é um momento mais descontraído, quando os noivos dão sorrisos mais naturais e acenam para a plateia. Os noivos recebem os cumprimentos na porta da igreja encerrando, assim, o ritual religioso casamento.

$\mathrm{Na}$ França, o encerramento com a bênção final e as assinaturas nos documentos são mais rápidas. Primeiramente os noivos assinam, depois são os padrinhos, enquanto isso, os convidados aos poucos vão saindo da igreja e formando um corredor a partir da porta. Quando os noivos saem, os convidados fazem a chuva de arroz, papel picado, pétalas de flores ou bolinhas de sabão.

\section{CONSIDERAÇÕES FINAIS}

Neste texto, procurou-se identificar que, na França, existem algumas diferenças no comportamento, nas escolhas e na organização do ritual em relação ao Brasil, que se refletem na própria espacialidade. Primeiramente, tem-se que desde antes de começar o ritual no Brasil enquanto o serviço de decoração é mais frequentemente realizado por um fornecedor, na 
França alguns familiares e amigos chegam à igreja antes e fazem pequenas intervenções na decoração da igreja.

No Brasil a noiva fica aguardando no interior do carro para que ninguém a veja até que todos entrem e inicie o ritual, sendo quase um interdito ver a noiva antes de sua entrada na nave da igreja. Somente após a entrada de todos é que ela sai do carro, após o comando do cerimonialista, profissional que está no comando do evento. Na França, geralmente a noiva chega antes, podendo ser de carro ou às vezes a pé, pois em várias igrejas não é possível chegar de carro até a porta de entrada, pois possuem praças ou calçadas que não permitem o acesso de carro. O mais comum é a noiva chegar e ficar na frente da igreja conversando e tirando fotos com seus familiares e amigos até que chegue a hora marcada do início do ritual. Assim, todos interagem, noivos, familiares e convidados até a hora marcada do casamento.

No Brasil é comum as noivas contratarem o serviço de assessoria e cerimonial para a organização de todos os passos do ritual, dado que o ritual religioso tem um caráter mais formal, pois se pode celebrar também a união civil. Na França não é costumeiro ter um(a) cerimonialista para fazer a organização da ordem do cortejo e o ritual civil é feito obrigatoriamente na mairie. Então, o padre mesmo passa as instruções estritamente relacionadas aos ritos religiosos para os noivos, pais e padrinhos a fim acertar os detalhes da cerimônia, tanto das entradas, quanto dos direcionamentos e posicionamentos dentro da igreja. Conforme informação obtida na secretaria da igreja informalmente, em Paris, o serviço cerimonial é muito caro, portanto são poucos os casais que o contratam - somente os que possuem mais recursos financeiros. Estes mais abastados sim fazem a contratação de cerimonialistas, coral ou orquestras, entre outros.

No Brasil o padre aguarda todos os participantes dos cortejos no altar. Na França, o sacerdote também participa do cortejo, ele é o primeiro a entrar pela nave da igreja; e as músicas normalmente são cantadas pelos sacerdotes e tocadas no próprio órgão das igrejas centenárias, onde as notas musicais ecoam com uma sonoridade imponente. Às vezes, há algum(a) músico(a) ou amigos dos noivos que fazem a parte vocal, embora seja comum os convidados participarem nas canções. No Brasil, diferentemente, o padre não canta no ritual e os noivos contratam este serviço e, muitas vezes, até um coral completo. Além de que as músicas não são somente "religiosas", pois se ouvem muito os temas de filmes hollywoodianos.

Na França, os pais e padrinhos não participam do cortejo, como no Brasil costuma-se fazer. Lembrando que na França os pais e padrinhos nunca ficam no altar, sempre estão 
posicionados na primeira fileira dos convidados. Em solo francês, é usual ter como padrinhos duas pessoas de cada lado, não importa o sexo; porém, no Brasil é tradicional compor o par por homem e mulher, além da quantidade que tem sido bem acima de dois padrinhos de cada lado.

No Brasil, os convidados são os últimos a saírem da igreja, mas na França são os primeiros e aguardam os noivos do lado de fora da igreja para dar os cumprimentos. Em ambos os países, enquanto a cerimônia se desenrola, a troca de olhares e sorrisos entre os noivos são costumeiros.

Dessa maneira, os casamentos são rituais que possuem movimento e uma interação espacial dos sujeitos durante toda a celebração, que se inicia desde a aproximação dos convidados e o posicionamento deles na igreja, a entrada do noivo, padrinhos, damas de honra e pajens até a triunfal chegada da noiva, se estendendo à saída. Tudo isto confere lugaridade à igreja segundo a cultura e as tradições locais.

\section{REFERÊNCIAS}

FRANCISCO. Exortação Apostólica Pós-Sinodal Amoris Lætitia. Disponível em http://w2.vatican.va/content/francesco/pt/apost_exhortations/documents/papafrancesco_esortazione-ap_20160319_amoris-laetitia.html. Acesso em 28/03/17.

FREITAS, Marta Helena de et al . Os sentidos do sentido: uma leitura fenomenológica. Rev. abordagem gestalt., Goiânia , v. 18, n. 2, p. 144-154, dez. 2012 . Disponível em $<$ http://pepsic.bvsalud.org/scielo.php?script=sci_arttext\&pid=S1809$68672012000200004 \& \operatorname{lng}=$ pt\&nrm=iso>. acessos em 04 abr. 2017.

GENNEP, Arnold van. Os Ritos de Passagem. 2 ed., Petrópolis: Vozes, 2011, 184 p.

LOPES, Rita de Cassia Sobreira et al. Ritual de casamento e planejamento do primeiro filho. Psicologia em estudo. Maringá. Vol. 11, n. 1 (jan./abr. 2006), p. 55-61., 2006.

MACHADO, João Carlos. Três paradigmas para a cenografia: instrumentos para a cena contemporânea. Cena, n. 2006. 5, Disponível em: http://seer.ufrgs.br/index.php/cena/article/view/9024/5179 Acesso em 28/03/17.

MAIA, Carlos Eduardo Santos Maia. Ritual e emoção nas interações espaciais - repensando o espaço sagrado nas festas populares de romarias e folguedos (notas introdutórias). In: Rosendahl, Zeny. Trilhas do sagrado. Rio de Janeiro: EdUERJ, 2010. p. 87-111.

PARKIN, D. Ritual as spatial direction and bodily division. In: COPPET, D. Understanding ritual. Londres: Routeledge, 1992, p. 11-25. 
PARÓQUIA NOSSA SENHORA DO BRASIL. Paróquia. Disponível em: <http://www.nossasenhoradobrasil.com.br/paroquia>. Acesso em: 08 abr. 2014.

PEIRANO, Mariza. Rituais Ontem e Hoje. Rio de Janeiro: Jorge Zahar ed. 2003, 57 p.

RHEIMS, Maurice. História do mobiliário. In: POIRIER, Jean. História dos Costumes: o homem e o objecto. Lisboa, Editorial Estampa, 3 vol., 1999, 127-186 pp.

THOMSON, Oliver. História do Pecado. Lisboa: Gerra e Paz, 1993, 375 p.

VILHENA, Maria A. Ritos: expressões e propriedades. São Paulo, Paulinas, 2005, 159 p. 